\title{
Young People's Reading and Information Use at the End of the Century
}

\author{
Sand ra Olën, Ph.D. \\ <olensii@alpha.unisa.ac.za> \\ Senior Lecturer \\ Department of Information Science, University of South Africa \\ South Africa
}

Amy Chamberlain

Myrna Machet, Ph.D.

\author{
Lecturer \\ Department of Information Science, University of South Africa \\ South Africa
}

\begin{abstract}
This paper presents a pilot research project carried out in five schools in a specific district in a province of South Africa, the survey methodology followed, as well as some of the key findings. This survey is based on a similar survey of young people's reading and information use carried out in the United Kingdom in 1995 and 1996. It provides information on young people's reading which is useful for publishers, librarians, writers, illustrators, teachers, and parents.
\end{abstract}

\section{Introduction}

This paper will focus on the 1997 pilot project in secondary schools in District N3 of the Gauteng Department of Education conducted by the Children's Literature Research Unit, which examined and will continue to study South African children's reading and their information use in South Africa. This project is part of a greater study carried out by The Children's Literature Research Centre, Roehampton Institute in London, UK, which examined what young people are reading at the end of the 20th century. The pilot phase which began in 1993 was completed in 1994 and a report on this phase entitled Contemporary juvenile reading habits: a study of young people's reading at the end of the century (1994) was compiled. The main research project was carried out in 1995-96 and resulted in the publication of Young people's reading at the end of the century (1996). Following the success of the British based study researchers from Roehampton Institute proposed that similar studies be conducted in other countries, such as South Africa. The Children's Literature Research Unit (CLRU) in the Department of Information Science at the University of South Africa (Unisa), Pretoria agreed to implement the research project, beginning with a pilot project. The CLRU thought that a preliminary project phase would offer insight into the most efficient ways of conducting a research project of this magnitude 
in a country undergoing great political and social change. This paper will present the methodology used and findings of this pilot project.

In many countries extensive research has been done on children's reading interests. To date no extensive research has been carried out in South Africa and although some isolated studies have been done over the past decades this work is already outdated because of political changes in South Africa. One of the reasons the CLRU decided to conduct this research project in South Africa was because of the real need for accurate information on children's reading and information use by people working in the fields of education, library and information science and publishing as well as for local authors and illustrators of books for children.

Without insight into children's reading habits, preferences and information use it is difficult for publishers, librarians, teachers and parents to motivate children and young people to read and use information. Information skills such as collecting, organizing and analyzing, and communicating ideas and information have been identified as key competencies for effective participation in the emerging patterns of work and work organization. In fact, they are essential competencies for effective functioning in today's world. It is assumed that Africans will follow Western models and patterns, however reliable information on their reading interests and information needs are required in order to provide effective library services, to publish and provide books they will find interesting so as to motivate reading and thus promote literacy.

The completed project aims to include a fair representation of South African learners in Grade 5 through to Grade 10. Only learners in the age group 10 to 16 will be included in the final analysis - although many students in South African schools are already over the age of 16 when they are still in Grades 9 and 10 their questionnaires will not be included in the survey results as they could be regarded as adults. The sample of students will take into account variables such as the 11 different official languages used in South Africa; gender; geographical location (i.e. rural and urban schools in all nine provinces of South Africa); type of school attended (i.e. government funded and private). The first phase of the pilot project, however, focuses only on secondary school students (Grades 8, 9, 10) in five Englishmedium schools in one school district of Gauteng Province's Department of Education.

\section{Research Questions}

The goals incorporated into the South African pilot project are to understand the relationship between reading and attitudes to a range of topical social issues; examine the ways in which children and young adults encounter and choose what to read; provide information about the reading habits and information use of children and young adults of different age, sex, class, ethnic background, geographical location and educational sector; and discern between conventional forms of reading (printed matter) and new developments in the presentation of and interactions with text (including audio tapes, video games, CD-ROMs). The CLRU intends to compile a database of the research findings, which will allow academics, librarians, publishers, authors, illustrators and parents to consult these so as to better understand what children and young adults would like to read. 


\section{Methodology}

Questionnaires

Dr. Kimberley Reynolds of The Children's Literature Research Centre, Roehampton Institute provided the CLRU with a copy of each of the questionnaires used for the different British key stages in their research project. Roehampton Institute holds the copyright to all these questionnaires, but Dr Reynolds agreed with the CLRU's suggestion that the questionnaires needed some modifications for use with South African learners. As the resarchers at the CLRU had decided not to survey learners in Grades 1 to 4 it was not necessary to use the questionnaire for key stage 1. Researchers at Roehampton Institute had found that teachers needed to help these very young learners to complete the questionnaires and that this was a very time-consuming process. The questionnaire for key stage 2 is appropriate for Grades 5 to 7 in the primary schools and the questionnaire developed for both key stages 3 and 4 is appropriate for Grades 8 to 10 in the secondary schools. Many questions simply required terminology changes (e.g. "newsagents" to "supermarkets" and "films" to "movies"). Some terms were omitted which the CLRU thought were pertinent to British learners only (e.g. "charity shops" and "specialist hobby shops"). Conversely, the CLRU added questions and terminology which were relevant to South Africans, or were considered essential to understanding all aspects of literacy in South Africa (for example, questions on oral traditions). All changes made to questionnaires were for purposes of clarity and relevance in South Africa. Researchers presented the questionnaires to youth librarians from the main and Mamelodi branches of the Pretoria City Library and to students in the Department of Information Science at Unisa in order to receive comments and suggestions from the perspective of librarians and different ethnic groups. Furthermore, the Sociology, Religion, and African Languages Departments at Unisa were contacted to determine proper terms for common religious affiliations and a complete list of the official languages in South Africa. Otherwise, as few textual changes as possible were made to the Roehampton questionnaires in order to ensure that many of the results could be compared.

Permission was sought from the Education Research Unit of the Gauteng Department of Education to carry out the pilot phase of the research project in schools in one of the 16 school districts under their jurisdiction. They requested that a number of organizations, such as the READ organization (a South African NGO: Read Educate and Develop), be contacted to ensure no overlap in research. They also requested some changes to the format of the questionnaire. The request was to divide the lengthy questionnaire for key stages 3 and 4 into three separate questionnaires and the questionnaire for key stage 2 into two separate questionnaires. Using shorter questionnaires would enable learners to complete a questionnaire in a much shorter time as each learner would still complete one questionnaire apiece. However this meant that the researchers had to use three times the number of secondary school learners and double the number of primary school learners in their samples than would have been used if only the original questionnaires had had to be completed by learners. The Educational Research Unit gave permission for the researchers at the CLRU to use schools in District N3 and provided a complete list of all the schools in this district so that a sample could be drawn. 
After a pretest of the questionnaires using volunteer learners who were not part of the sample, it was decided that one class period of forty minutes was necessary for a researcher to explain the project, introduce the questionnaires, and answer any questions from learners before and during their administration.

Questionnaires were distributed to students between September 12, 1997, and October 10, 1997. Between October and December, questionnaires were checked, coded, and loaded onto SPSS, a statistical analysis and data management system also used by the researchers at Roehampton. The additional written information provided by respondents which could not be read statistically due to the _open_nature of the question would have to be interpreted by CLRU members for evaluation in a supplementary report.

\section{Ethics}

Throughout the pilot project great care was taken to keep research ethics in mind. The privacy/confidentiality of respondents was respected as no young person participating in the project was required to answer any questions to which s/he took exception. Furthermore, all students were guaranteed that questionnaires would be and will remain anonymous; no names or identifying numbers were attached to the questionnaires which were collected and placed in envelopes. The CLRU's researchers thought that to ensure students gave as truthful responses as possible they should not be inhibited by their teachers.

Each school that participated in the project received some donated and specially purchased books as a gesture of appreciation for their assistance and the principal was informed that a copy of the final report would be supplied.

\section{Sample design}

Schools under the jurisdiction of the Gauteng Department of Education may only be surveyed between the months of April and September. Therefore, it was decided to divide the pilot project into two phases. Students in the secondary English-medium schools in district N3 would be surveyed before October 1997 and pupils in primary schools would be surveyed in April and May of 1998. A list of all 236 schools in district N3 and revealed that there were 47 secondary schools (or combined schools), 36 English schools, and 11 Afrikaans schools. ${ }^{2}$

The 36 English secondary schools included 17 state and state-aided secondary schools (includes 2 rural combined schools) ${ }^{3}, 8$ private secondary schools, and 11 combined (primary and secondary) private schools.

The number of students in N3 secondary schools in 1997 was 25,775 (includes Afrikaans schools, technical schools as well as students in Grades 11 and 12 in all schools). The total number of students in Grades 8, 9, and 10 in English schools could not be determined and as the sample should comprise $5 \%$ of these students it was decided to use $10 \%$ of the English-medium schools in the district in the hope that this would ensure a sample of approximately, if not more than $5 \%$. 
Most schools in South Africa are coeducational; the only single-sex schools are convent schools and a boy's and girl's high school (see sample of schools drawn below). There was no conscious attempt to work with these single-sex schools as it was a randomly drawn sample. As for gender breakdowns, the ratio of girl to boy learners is roughly fifty-fifty.

In order to provide a representative sample taking the all variables into account, the CLRU researchers met with statistical consultants in the Department of Statistics at Unisa to decide how many schools were needed to acquire a representative sample. Once the schools were divided into the categories noted above, a volunteer randomly chose one school from each envelope (containing slips of paper with each schools' name). The sample included the following:

- secondary, urban, state-funded, single sex school

- combined, urban, private, single-sex school

- secondary, urban, state-funded, coed school

- secondary, urban, private, coed school

- secondary, urban, state-funded, coed school.

\section{Fieldwork}

School principals were approached and asked to participate in the project. All schools agreed, although some asked that a preliminary meeting be set up in order to learn more about the project. Although the CLRU originally planned (Children's Literature Research Centre Roehampton Institute 1996:v) to conduct interviews with a small sample of learners at participating schools, the CLRU was unable to implement this aspect of the research project for time efficiency reasons.

\section{Validity of the responses}

All errors recorded from the pilot project survey results will be examined and remedied prior to commencing follow-up phases. At least two researchers from the CLRU were present during administration of questionnaires in order to answer questions and explain phrasing or certain terms. For example, researchers found that many students were uncertain as to the meaning of "sibling," "dialogue" and "fiction." Each survey session began by writing these three words on the blackboard and defining them aloud to the class.

Many of the African students who use English as a second or third language, had difficulty understanding many of the questions. When the questionnaires for the primary schools (two for key stage 2) were translated into Tswana and Northern Sotho (two of the most commonly spoken African languages in Gauteng Province), it was learnt that there are no concepts for time gradation in the African languages. Therefore, questions asking a learner to indicate "never, hardly ever, sometimes, often, or very often" are most likely to be misunderstood by African students whose time frames include "doing something" or "not doing something" (for example "visit the library" or "not visit the library"). Researchers found this may explain 
why many of the African students participating in the survey had problems filling out certain parts of the questionnaire. Cultural implications are important to note for further phases, and certainly must be taken into consideration when examining data validity for some questions posed in the pilot project.

Researchers found when examining the collected questionnaires that many students chose to omit certain questions, leaving blank answers. Other students who perhaps misunderstood the question (see reasons noted above) left open certain answers. These "incorrect" or "blank" responses were read by the computer as "missing cases." Therefore, computer data was supplied in two sets of percentages: one encompassing all learners participating in a given questionnaire (i.e., 154 boys for Q4), and another for valid cases only (after filtering out "missing cases"). Certain sections generated more "missing cases" than others, such as Poetry in Q4, which gave students the option to skip the entire section after answering "no" to the first question ("Do you ever read poetry?").

Another issue was the discarding of questionnaires altogether after collecting them from students. The researchers decided that if less than two-thirds of a questionnaire had been completed, it must be discarded. Furthermore, all questionnaires completed by participating students whose age did not fall within the set sample limits (10-16 years) had to be discarded. This proved to be a greater problem when surveying students in schools where some of them were aged 17 to 21 in grades 8,9 and 10. For example, the urban township school enrolled many older students who lacked adequate English language skills and were therefore "behind" the average age for that grade. Because so many questionnaires had to be discarded, the researchers were disappointed that survey results would not be representational.

\section{Survey details}

The sample selected for phase 1 of the pilot study consisted of five schools and 958 participants with 877 respondents (key stages 3 and 4). However, this number should be divided by three as the questionnaire for these key stages was divided into three separate questionnaires. This results in a much smaller number of only 292.3 full questionnaire equivalents. It would have been desirable to ascertain what percentage this was of the total number of students in grades 8 to 10 in District N3 at the time, because 292.3 appears to be considerably less than the required $5 \%$. The similarity between the numbers of 14,15 , and 16 year-olds means that the sample used in the pilot project is a reasonable representation of 8 th, 9 th and 10 th graders.

\section{Key Findings}

Time constraints do not permit a detailed discussion of the findings. This paper therefore highlights some of the key findings of the pilot study, as well as some similarities and discrepancies between these key findings and those of the original survey in the United Kingdom. 


\section{How young people choose books and comics}

When choosing what to read young people are more influenced by external attributes than by reflections of themselves in texts. In the United Kingdom (UK) survey nearly half of the young people surveyed say they choose the books they read because of the title and in the South African (SA) survey an interesting title was also an important factor with the boys who say they "often" or "very often" choose a book because of its title being $49.6 \%$ and the girls $53.3 \%$. In SA media (TV, radio, book review, or audio tape version) had very little impact on the respondents choice of a book. On the issue of books in home languages, boys' responses were divided between "very often" (32\%) and "never" $(32.7 \%)$, whereas $46.8 \%$ of the girls claimed this factor is never an issue in their book selection. In the UK survey the blurb on the back or inside the cover was major factor in book choice for young people aged between 11 and 16 years; girls of this age said blurb and title are the most important factors affecting the way in which they chose books to read.

In the UK survey when young people chose a book because of the appearance of the cover, it is because "it looks up-to-date/modern." In the SA survey a modern look was also the most important factor by young people who are influenced by the cover's appearance ("often" $24.1 \%$ of the boys and $20.8 \%$ of the girls). Young people are influenced by fashions (clothes, music, and graphics), because books are obviously also part of this process, their covers need to be modern or fashionable.

One of the questions which was added to the SA survey was "Do you prefer reading books in Afrikaans, English or in an African language?" in order to determine what language preferences are being adopted by South Africans of the next generation. Interestingly, the vast majority of students $(97.1 \%$ of boys and $98.4 \%$ of girls say they prefer to read English books. Although only one student chose Afrikaans this was not surprising as the survey excluded schools where Afrikaans is the language of instruction. Only $2.1 \%$ of boys and $1.6 \%$ of girls opted for books in an African language.

South African respondents read more magazines (93.9\% boys and $97.9 \%$ girls) than comics (boys $77.6 \%$ and girls $72.9 \%$ ) and their reasons for choosing magazines and comics were confined primarily to three of the options: you like its appearance, you like the illustrations, you think it is good value for money.

\section{Thinking about fiction}

The 1996 UK survey revealed that horror is the most popular fiction genre for adolescents. While romance is the least popular choice for boys across all the ages, it is also not a popular choice for girls except at ages 14 to 16 years $(38.6 \%)$. Humor is also are popular with students of all ages.

In the SA survey the most popular fiction genres for the girl respondents were romantic stories $(53.3 \%)$, school stories (47\%), mysteries (40.6\%), and religious stories $(37.3 \%)$. Only $36 \%$ of the girls indicated that they "often" or "very often" read horror stories. However, the most popular fiction genre for SA boys was horror (42\%), but this choice is closely followed by humor stories $(38.9 \%)$ and mysteries $(37.4 \%)$. It is possible that horror stories are not as popular in SA, particularly amongst township youth, because many of these young people are 
exposed to a high level of violence and crime in their daily lives and so may have less desire to read about it.

\section{Out of school (and after-school) activities}

The four out-of-school/after-school activities preferred by the boys in the SA survey are sports $(48.6 \%)$, listening to music on tapes/records/CDs $(48.1 \%)$, playing with friends (37.1\%), and watching TV (34.5\%). The three activities preferred by the girls are listening to music on tapes/records/CDs $(49.6 \%)$, watching TV $(41.5 \%)$, and listening to the radio (40.7\%). More girls than boys spend time reading fiction for fun, but the most common answer for both genders is that they spend very little time (less than one hour per week) on this activity.

In the SA survey $58.9 \%$ of the boys claim to be average readers while $59.3 \%$ of the girls say they are average readers. More girls $(21.3 \%)$ are enthusiastic about reading than boys $(20.2 \%)$, and fewer girls $(19.4 \%)$ than boys $(21 \%)$ state that they are reluctant readers but these differences are very small. The UK survey findings in this regard were dissimilar because twice as many boys $(23.2 \%)$ as girls $(11.5 \%)$ regard themselves as reluctant readers.

\section{Reading for information}

In the UK magazines are young people's favorite form of factual reading. In SA, however, more boys indicated that they prefer reading about social issues in newspapers $(40.6 \%)$ than in magazines (36.1\%). South African girls prefer reading about social issues in magazines $(41.7 \%)$ but also like to read about these issues in novels/stories $(20.9 \%)$. The UK survey found that girls' favourite non-fiction reading is about animals and plants, but SA girls favorite was reading about their bodies. Sport is the most popular nonfiction subject with SA boys. Overall this section on reading for information generated a greater number of responses and also more positive responses from the boys suggesting that more boys than girls prefer reading nonfiction.

\section{Conclusions}

A great deal of information has been collected in the first phase of this South African pilot project and there are both interesting similarities, but also a number of differences, when these findings are compared to those of the larger survey carried out in the United Kingdom. The appearance of books and comics significantly affects their appeal to young people. Magazines and newspapers are important sources of information for young people, yet in SA there are no magazines or newspapers specifically published for teenagers as is the case in many other countries such as the UK, USA and Canada. It is hoped that these surveys will provide writers, publishers, illustrators, librarians, teachers, and parents with valuable insights into young people's reading preferences and information use. 


\section{Notes}

1. The authors would like to thank Thomas van der Walt and Dr Felicité Fairer-Wessels of the Children's Literature Research Unit in the Dept of Information Science for their assistance in carrying out the survey.

2. (A postgraduate Masters student in the Dept of Information Science at Unisa is carrying out research within Afrikaans medium secondary schools for her Masters degree)

3. It was agreed not to separate the schools between urban, rural and township because there are only two rural (combined) schools in N3, making the figures too insignificant to count separately, so they were included in the 17 state and state-aided schools.

\section{References}

Contemporary juvenile reading habits: A study of young people's reading at the end of the century. (1994). London: Children's Literature Research Centre, Roehampton Institute.

Young people's reading at the end of the century. (1996). London: Children's Literature Research Centre, Roehampton Institute. 